\title{
The effect of sorafenib on hepatic stellate cells: implication of its effect on tumor microenvironment
}

\author{
Jung II Lee
}

Department of Internal Medicine, Division of Gastroenterology, Inha University School of Medicine, Incheon, Korea

\author{
New insights into the antifibrotic effects of sorafenib on \\ hepatic stellate cells and liver fibrosis.
}

\author{
Wang Y, Gao J, Zhang D, Zhang J, Ma J, Jiang H. \\ J hepatol 2010;53:132-144.
}

Sorafenib is a multiple receptor tyrosine kinase inhibitor that has been shown to improve the survival of patients with advanced hepatocellular carcinoma (HCC). ${ }^{1,2}$ It acts by blocking the receptor tyrosine kinases such as vascular endothelial growth factor receptors (VEGFR), platelet derived growth factor receptor (PDGFR), c-Kit, fibroblast growth factor receptor-1, and the serine/threonine kinase RAF, thereby repressing cell proliferation and angiogenesis. ${ }^{3,4}$ The drug is currently considered as the standard of care in patients with advanced HCC and preserved liver function. ${ }^{5}$ Unfortunately, majority of patients with advanced HCC still die from the disease despite of the sorafenib treatment. In order to satisfy the unmet need in treating advanced $\mathrm{HCC}$, additional investigation is required to clarify the molecular pathogenesis of HCC. Understanding the mechanism of action of sorafenib, both on tumor and non-tumor tissue, would be a step forward.

Multiple kinases that are suppressed by sorafenib not only involve in the survival of tumor cells themselves but also that of other cells surrounding the tumor tissue. There have been growing evidences that this surrounding tissue, so called the tumor microenvironments, would play an important role in tumoregenesis, tumor invasion and metastasis. ${ }^{6,7}$ The tumor microenvironments of $\mathrm{HCC}$ include cells such as hepatic stellate cells (HSCs) and immune cells, growth factors, proteolytic enzymes, extracellular matrix and inflammatory cytokines.

HSCs are activated in response to liver damage. The repeated injury would result in liver fibrosis. ${ }^{8}$ In addition, activated HSCs may infiltrate the stroma of liver tumors and localize around tumor sinusoids, fibrous septa and capsules. ${ }^{9}$ It has been reported that the media collected from HSCs induced proliferation and migration of HCC cells, cultured in monolayers. It also has been demonstrated that simultaneous in vivo implantation of HSCs and HCC cells into nude mice promoted tumor growth and invasiveness when necrosis was inhibited. ${ }^{10}$

The study by Wang et $\mathrm{al}^{11}$ reported the effect of sorafenib on HSCs in vitro and liver fibrosis in vivo. On two separate liver fibrosis animal models, one induced by bile duct ligation and the other chemically induced by intraperitoneal dimethylnitrosamine (DMN), sorafenib attenuated liver fibrosis. Liver fibrosis was histologically evaluated by Masson's trichrome collagen staining and quantification of collagen production. However, the behavior of HSCs upon sorafenib treatment in vivo was not fully investigated in this particular study. The effect of sorafenib on HSC proliferation and apoptosis were shown only on HSC cell lines. Although the assumption could be made that the anti-fibrotic effect was caused by sorafenib on HSCs, being the key player in liver fibrosis, more solid evidence would be preferred. This evi-

\footnotetext{
Keywords: Sorafenib; Hepatocellular carcinoma; Stellate cell

Abbreviations: HCC, hepatocellular carcinoma; VEGFR, vascular endothelial growth factor receptor; PDGFR, platelet derived growth factor receptor; HSC, hepatic stellate cell; DMN, dimethylnitrosamine; ALT, alanine aminotransferase

Corresponding author: Jung Il Lee

Department of Internal Medicine, Division of Gastroenterology, Inha University School of Medicine, 7-206 3-ga, Sinheung-dong, Jung-gu, Incheon 400-711, Korea

Tel. +82-32-890-2548, Fax. +82-32-890-2549, E-mail; mdflorence@inha.ac.kr
}

Copyrights (C) 2010 by The Korean Association for the Study of the Liver The Korean Journal of Hepatology • pISSN: 1738-222X eISSN: 2093-8047 
dence came from the study by Hennenberg et $\mathrm{al}^{12}$ that was recently published. The study showed the decreased number of $\alpha$-smooth muscle actin positive cells in bile duct ligated rats after sorafenib administration. ${ }^{12}$

Both Wang and Hennenberg studies emphasized the role of sorafenib as antifibrotic agent. These studies support the previous investigations reporting the beneficial effect of sorafenib on portal hypertension. ${ }^{13,14}$ However, translation and clinical application of these results in treating portal hypertension and cirrhosis still have to undergo very carefully. In vivo studies, including the one performed by Wang $\mathrm{Y}$ et al, showed aggravation in liver parameters such as serum alanine aminotransferase (ALT) by certain concentration of sorafenib. Instead, the effect of sorafenib on HSCs rather implies that sorafenib not only suppresses the tumor cells themselves but also attenuates the tumor microenvironments that might have cross-talk with the cancer cells. Evaluating the effect of sorafenib on HSCs surrounding HCC would provide better perspective on this. In addition, understanding the behavior of sorafenib on the tissue surrounding the tumor might give more clues for pathogenesis of HCC thus better strategy against HCC. There has been growing number of reports over the recent years that emphasized the role of tumor microenvironments. It appears that tumor cells, once thought to be autonomous, seem to depend on angiogenesis, inflammatory cells and fibroblasts. ${ }^{15-17}$ Therefore it would be ideal if the treatment were to target tumor-microenvironment interaction that stimulated tumor progression, invasion and metastasis as well as hepatocarcinogenesis. Further studies evaluating how sorafenib meet this goal would be a great resource in developing new drugs that could be used alone or in combination with sorafenib.

In summary, evidences that show anti-fibrotic effect of sorafenib through suppressing HSCs has been reported. Implication and use of this information may need further contemplation.

\section{REFERENCES}

1. Llovet JM, Ricci S, Mazzaferro V, Hilgard P, Gane E, Blanc JF, et al. Sorafenib in advanced hepatocellular carcinoma. N Engl J Med
2008:359:378-390.

2. Cheng AL, Kang YK, Chen Z, Tsao CJ, Qin S, Kim JS, et al. Efficacy and safety of sorafenib in patients in the Asia-Pacific region with advanced hepatocellular carcinoma: a phase III randomised, double-blind, placebo-controlled trial. Lancet Oncol 2009;10:25-34.

3. Wilhelm SM, Carter C, Tang L, Wilkie D, McNabola A, Rong H, et al. BAY 43-9006 exhibits broad spectrum oral antitumor activity and targets the RAF/MEK/ERK pathway and receptor tyrosine kinases involved in tumor progression and angiogenesis. Cancer Res 2004; 64:7099-7109.

4. Wilhelm SM, Adnane L, Newell P, Villanueva A, Llovet JM, Lynch M, et al. Preclinical overview of sorafenib, a multikinase inhibitor that targets both Raf and VEGF and PDGF receptor tyrosine kinase signaling. Mol Cancer Ther 2008;7:3129-3140.

5. Chew V, Tow C, Teo M, Wong HL, Chan J, Cehring A, et al. Inflammatory tumour microenvironment is associated with superior survival in hepatocellular carcinoma patients. J Hepatol 2010;52:370-379.

6. Kudo M, Ueshima K. Positioning of a molecular-targeted agent, sorafenib, in the treatment algorithm for hepatocellular carcinoma and implication of many complete remission cases in Japan. Oncology 2010;78(suppl 1):154-166.

7. Yang JD, Nakamura I, Roberts LR. The tumor microenvironment in hepatocellular carcinoma: Current status and therapeutic targets. Semin Cancer Biol 2010 Oct 12. [Epub ahead of print]

8. Wynn TA. Cellular and molecular mechanisms of fibrosis. J Pathol 2008;214:199-210.

9. Dubuisson L, Lepreux S, Bioulac-Sage P, Balabaud C, Costa AM, Rosenbaum J, et al. Expression and cellular localization of fibrillin-1 in normal and pathological human liver. J Hepatol 2001;34:514-522.

10. Amann T, Bataille F, Spruss T, Muhlbauer M, Gabele E, Scholmerich J, et al. Activated hepatic stellate cells promote tumorigenicity of hepatocellular carcinoma. Cancer Sci 2009;100:646-653.

11. Wang Y, Gao J, Zhang D, Zhang J, Ma J, Jiang H. New insights into the antifibrotic effects of sorafenib on hepatic stellate cells and liver fibrosis. J hepatol 2010;53:132-144.

12. Hennenberg M, Trebicka J, Kohistani Z, Stark C, Nischalke HD, Krämer B, et al. Hepatic and HSC-specific sorafenib effects in rats with established secondary biliary cirrhosis. Lab Invest 2010 Oct 4. [Epub ahead of print]

13. Reiberger T, Angermayr B, Schwabl P, Rohr-Udilova N, Mitterhauser M, Gangl A, et al. Sorafenib attenuates the portal hypertensive syndrome in partial portal vein ligated reats. J Hepatol 2009;51:865-873.

14. Mejias M, Garcia-Pras E, Tiani C, Miquel R, Bosch J, Fernandez M. Beneficial effects of sorafenib on splanchnic, intrahepatic, and portocollateral circulations in portal hypertensive and cirrhotic rats. Hepatology 2009;49:1245-1256.

15. Severi T, van Malenstein H, Verslype C, van Pelt JF. Tumor initiation and progression in hepatocellular carcinoma: risk factors, classification, and therapeutic targets. Acta Pharmacol Sin 2010;31:1409-1420.

16. Mantovani A, Allavena P, Sica A, Balkwill F. Cancer-related inflammation. Nature 2008;454:436-444.

17. Kalluri R, Zeisberg M. Fibroblasts in cancer. Nat Rev Cancer 2006; 6:392-401. 